Available at: https://optn.transplant.hrsa.gov/media/3701/data_report_thoracic_ committee_heart_subcommittee_20200227_rpt1_revised_508_compliant.pdf.

2. Zhu Y, Shudo Y, Lingala B, Baiocchi M, Oyer PE, Woo YJ. Outcomes after heart retransplantation: a 50-year single-center experience. J Thorac Cardiovasc Surg. 2022;163:712-20.e6

3. Stinson EB, Dong E Jr, Schroeder JS, Harrison DC, Shumway NE. Initial clinical experience with heart transplantation. Am J Cardiol. 1968;22:791-803.

4. Robbins RC, Barlow CW, Oyer PE, Hunt SA, Miller JL, Reitz BA, et al. Thirty years of cardiac transplantation at Stanford University. J Thorac Cardiovasc Surg. 1999;117:939-91.

5. Takeda K, Li B, Garan AR, Topkara VK, Han J, Colombo PC, et al. Improved outcomes from extracorporeal membrane oxygenation versus ventricular assist device temporary support of primary graft dysfunction in heart transplant. J Heart Lung Transpl. 2017;36:650-6.
6. DeRoo SC, Takayama H, Nemeth S, Garan AR, Kurlansky P, Restaino S, et al. Extracorporeal membrane oxygenation for primary graft dysfunction after heart transplant. J Thorac Cardiovasc Surg. 2019;158:1576-84.e3

7. Karamlou T, Welke KF, McMullan DM, Cohen GA, Gelow J, Tibayan FA, et al. Combined heart-kidney transplant improves post-transplant survival compared with isolated heart transplant in recipients with reduced glomerular filtration rate: analysis of 593 combined heart-kidney transplants from the United Network Organ Sharing Database. J Thorac Cardiovasc Surg. 2014;147:456-61.e1.

8. Savla J, Lin KY, Pradhan M, Ruebner RL, Rogers RS, Haskins SS, et al. Heart retransplant recipients have better survival with concurrent kidney transplant than with heart retransplant alone. J Am Heart Assoc. 2015;4:e002435.

9. Gosev I, Kiernan MS, Eckman P, Soleimani B, Kilic A, Uriel N, et al. Long-term survival in patients receiving a continuous-flow left ventricular assist device. Ann Thorac Surg. 2018;105:696-701.
See Article page 712.

\section{Commentary: Heart transplant second chances: Retransplantation should be supported by allocation algorithms}

\section{James K. Kirklin, MD}

Zhu and colleagues ${ }^{1}$ provide an excellent review of an amazing 50-year experience in cardiac retransplantation. Seeing the simple notation in the Methods section of a clinical experience "from January $6,1968 . . . "$, my mind promptly returned to an era of intense global competition to perform the world's first human heart transplant. Of course, it all began with Norman Shumway's pioneering work in the early 1960s with his close friend and colleague Richard Lower. Through seminal scientific studies, Shumway and his team paved a path toward clinical application of this extraordinary therapy. There was no shortage of drama in those early days, as Shumway, Christian Barnard, and Adrian Kantrowitz raced to accomplish this feat. Barnard achieved first success on December 3, 1967, in what is among the most celebrated events in medical history.

From the Kirklin Institute for Research in Surgical Outcomes and Department of Surgery, University of Alabama at Birmingham, Birmingham, Ala.

Disclosures: Dr Kirklin receives partial salary paid to his institution for his role as director of a clinical coordinating center for the Society of Thoracic Surgeons Interagency Registry for Mechanically Assisted Circulatory Support.

The Journal policy requires editors and reviewers to disclose conflicts of interest and to decline handling or reviewing manuscripts for which they may have a conflict of interest. The editors and reviewers of this article have no conflicts of interest.

Received for publication July 10, 2020; revisions received July 10, 2020; accepted for publication July 10, 2020; available ahead of print July 15, 2020.

Address for reprints: James K. Kirklin, MD, Kirklin Institute for Research in Surgical Outcomes and Department of Surgery, University of Alabama at Birmingham, ZRB 739, 703 19th St, S, Birmingham, AL 35294 (E-mail: jkirklin@uabmc.edu).

J Thorac Cardiovasc Surg 2022;163:722-3

$0022-5223 / \$ 36.00$

Copyright (c) 2020 by The American Association for Thoracic Surgery

http://dx.doi.org/10.1016/j.jtcvs.2020.07.032
Check for updates

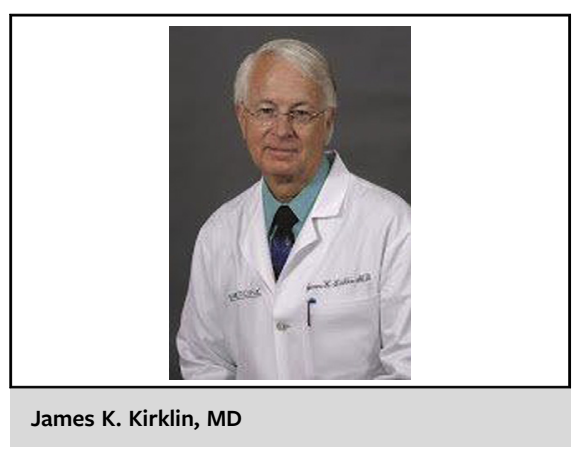

CENTRAL MESSAGE

After risk adjustment, cardiac retransplantation provides similar long-term survival as does primary transplant, supporting this lifesaving option in the heart transplant algorithm.

Shumway and his team performed the world's fourth human heart transplant on January 6, 1968, and because of his critical contributions, Shumway is widely recognized as the father of clinical heart transplantation.

When cyclosporine gained Food and Drug Administration approval for clinical use in 1983, the rapid improvement in heart transplant outcomes heralded a dramatic proliferation of programs and heart transplants, promptly exposing the Achilles' heel of this therapy: A shortage of donor organs. Predictably, ethical arguments abounded about the role of cardiac retransplantation: commitment to individual patients who are totally dependent on a transplanted heart for survival versus the community of advanced heart failure patients who 
will likely die without a heart transplant. Should each patient be allocated only 1 heart, or should we proceed with a second attempt if the first graft fails?

A major part of the controversy centers on the obligation to optimize utilization of limited organs in settings that maximize graft survival. Persuasive experts opine that inferior survival with cardiac retransplantation should limit its use. The Stanford group is by no means the first to examine this issue, but their study, through a propensity matching analysis, convincingly demonstrates the similar survival ( $\log$ rank $P=.36$ ) achieved with retransplant versus primary transplant in reasonably comparable patients. The period of discernable difference in survival was early after retransplant, providing the expectation for ongoing improvement in outcomes with current-generation posttransplant management and support techniques. This is very important information for the decision matrix.

Other things can be learned from their analysis. In real-world clinical experiences, the propensity matching exercise is statisticians' attempt to balance potential risk factors between cohorts, with the goal of isolating risk differentials associated with the treatments (in this case primary vs secondary transplant). However, certain factors relevant to only 1 group, such as indication for and timing of retransplant, cannot be included in the propensity score. Nestled within the analysis was the finding that patients undergoing retransplant within the first year $(23 \%$ of the cohort) experienced particularly poor survival (median survival, 0.2 years; 5-year survival, $20 \%$ ). Further, early graft failure dominated as the indication for retransplant during the first year, emphasizing the importance of improved methods of donor heart preservation, which have evolved over the past 2 decades.

This and other detailed studies on cardiac retransplantation can provide useful information not only to support this practice, but also to help characterize patient profiles that predict poor survival and therefore suboptimal organ use. The authors have added to the fine Stanford tradition of expanding our understanding of and expectations with this miraculous therapy.

\section{Reference}

1. Zhu Y, Shudo Y, Lingala B, Baiocchi M, Oyer PE, Woo YJ. Outcomes after heart retransplantation: a 50-year single-center experience. J Thorac Cardiovasc Surg. 2022;163:712-20.e6.

\section{Commentary: The role of mechanical circulatory support in heart retransplantation}

\author{
Yuji Kaku, MD, Koji Takeda, MD, PhD, and \\ Yoshifumi Naka, MD, PhD
}

Heart retransplantation remains the only definitive long-term treatment for end-stage cardiac allograft failure and accounts about $3 \%$ of all adult heart transplants. Several previous studies have reported that surgical outcomes in heart

\footnotetext{
From the Division of Cardiothoracic and Vascular Surgery, Department of Surgery, Columbia University Irving Medical Center, New York, NY.

Disclosures: The authors reported no conflicts of interest.

The Journal policy requires editors and reviewers to disclose conflicts of interest and to decline handling or reviewing manuscripts for which they may have a conflict of interest. The editors and reviewers of this article have no conflicts of interest.

Received for publication July 12, 2020; revisions received July 12, 2020; accepted for publication July 14, 2020; available ahead of print July 18, 2020.

Address for reprints: Yoshifumi Naka, MD, PhD, Division of Cardiothoracic and Vascular Surgery, Department of Surgery, Columbia University Irving Medical Center, New York, NY 10032 (E-mail: yn33@cumc.columbia.edu).

J Thorac Cardiovasc Surg 2022;163:723-4 $0022-5223 / \$ 36.00$

Copyright (C) 2020 Published by Elsevier Inc. on behalf of The American Association for Thoracic Surgery

http://dx.doi.org/10.1016/j.jtcvs.2020.07.047
}

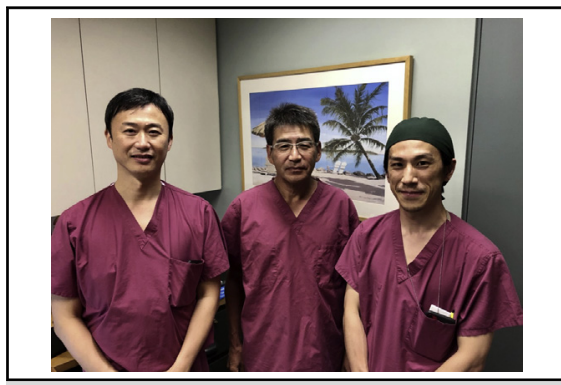

Koji Takeda, MD, PhD, Yoshifumi Naka, MD, PhD, and Yuji Kaku, MD

CENTRAL MESSAGE

Careful patient selection and good use of mechanical circulatory support may be a key to success in heart retransplantation. 